\title{
Nodular Fascitis of Zygoma- A Case Report
}

\author{
Koijam Shashi Kumar* \\ Directorate of Medical \& Health Services, Manipur, India
}

Received: November 15, 2017; Published: November 30, 2017

*Corresponding author: Shaahi Kumar, Directorate of Medical \& Health Services, Government of Manipur, Imphal, Manipur, India, Tel: 8974067254; Email: koijamsas@gmail.com

\section{Abstract}

Nodular Fasciitis is a benign reactive lesion of fibroblast that presents as a solitary, well circumscribed, rapidly growing soft tissue mass. It is most commonly located in the upper extremities, chest and trunk. Nodular fasciitis is rarely found in the Head \& Neck region. Although benign it can be associated with a malignant process because of its rapid growth. Hence accurate diagnosis is important to avoid unnecessary and often mutilating surgery. We present a case of nodular fasciitis over zygoma in a $10 \mathrm{yr}$ old child and its management.

\section{Introduction}

Nodular Fasciitis was first described by Konwaler, who named it pseudo sarcomatous fasciitis because of its resemblance to sarcoma. Nodular Fasciitis is also known as psedosarcomatous fibromatosis, proliferative fasciitis and infiltrative fasciitis [1-4]. It is an idiopathic, reactive, self limited proliferation of fibroblast and myofibroblast most commonly found in subcutaneous tissue. It commonly presents as a solitary, well circumscribed, rapidly growing soft tissue mass that may be painful of tender. Lesions most commonly occurs on upper extremities (43\%), followed by trunk (25\%), lower extremities (43\%) and head \& neck (10\%). Although head \& neck region is rare in adults, it is the most common site in pediatric population. Has an approximately equal sex distribution. Nodular Fasciitis is a benign lesion that can often be confused with myofibromatosis or a sarcoma due to its rapid growth, rich cellularity and mitotic activity. Hence it is important to distinguish the lesion from a more aggressive condition [5-10].

\section{Case Presentation}

A 10 year old child was referred to our college from a child hospital with a provisional diagnosis of osteoma of zygomatic bone. History reveled that there was presence of a small painless progressively enlarging swelling over right zygoma region for past 2months [11-13]. On examination, a single solitary nodule of size $1.5 \times 1.5 \mathrm{~cm}$, spherical in shape was seen over the area of right zygoma (Figure 1). The lesion was firm; surface was smooth and fixed to the underlying zygomatic bone. On applying pressure firmly in an upward and downward direction, slight mobility can be appreciated. Conventional x-ray was taken and it revealed a soft tissue density mass [14-17]. FNAC was performed and it was suggestive of an osteoma. Following the FNAC, an ultrasonography was done which revealed a well-defined homogenous hypoechoic mass with slight internal echo lateral to right zygomatic arch and features were suggestive of a benign soft tissue lesion (Figure 2). There was evidence of tissue intervening the lesion and the outer surface of zygomatic arch [17-21]. On doppler ultrasonography, no evidence of internal vascularity was found. Following the findings in ultrasonography, another FNAC was repeated for the second time and report was suggestive of a spindle cell neoplasm probably neural or fibrohistocytic lesion. As the patient was only 10 years old and a soft tissue lesion was suspected, an MRI was planned. Urea and creatinine test was done and it was within the normal range. An MRI was taken and it reveled $15 \times 10 \times 10 \mathrm{~mm}$ well-defined T1 isointense and T2 hyper intense lesion in subcutaneous plane over the right zygomatic arch (Figure 3). The lesion is not suppressed on fat-saturation sequence. The lesion is not eroding the underlying bone.

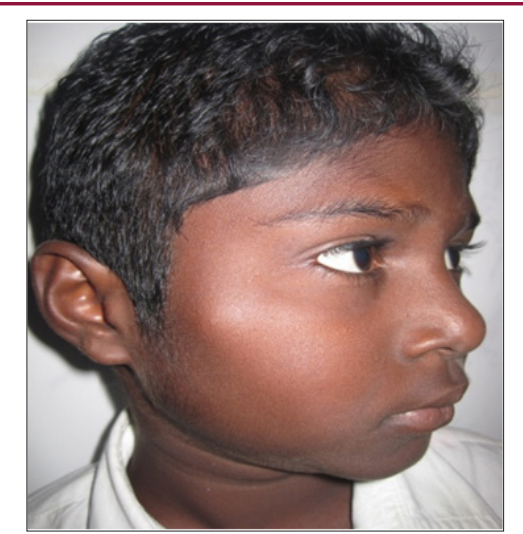

Figure 1: Spherical in shape was seen over the area of right zygoma. 


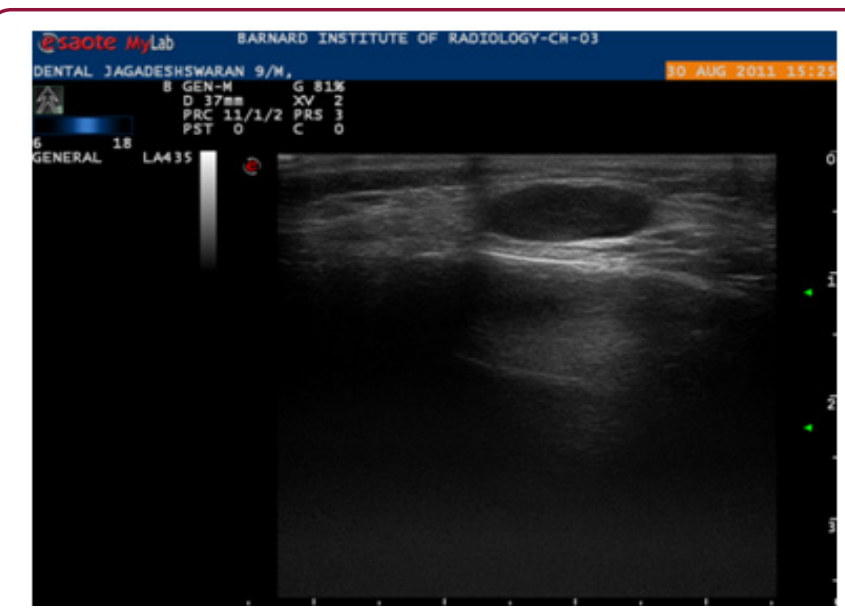

Figure 2: Homogenous Hypoechoic Mass with Slight Internal Echo Lateral to Right Zygomatic arch and Features were Suggestive of a Benign Soft Tissue Lesion.
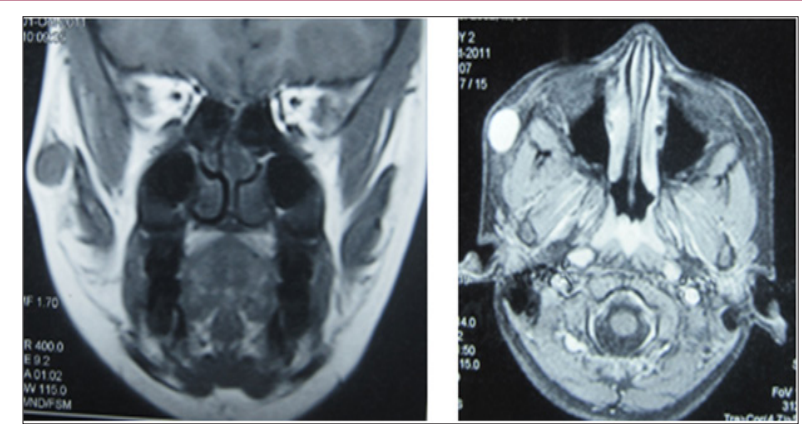

Figure 3: T1 Isointense and T2 hyperintense lesion in subcutaneous plane over the right zygomatic arch.

\section{Surgical procedure}

The patient was taken up for local surgical excision. Through a transfacial approach an incision was made along the direction of the relaxed skin tension lines. Layer wise dissection done to reach the plane of the lesion. The mass was easily dissected out from the surrounding tissues and was submitted for histopathology.

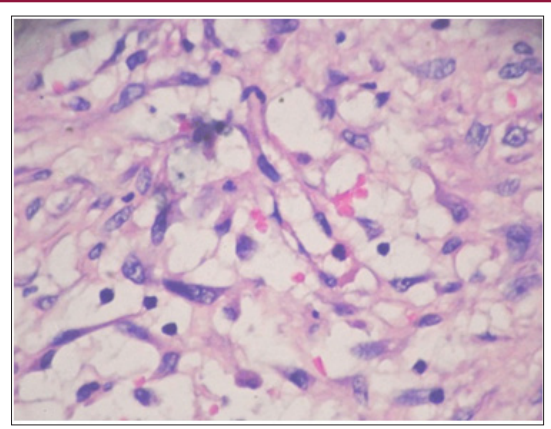

Figure 4: Mitosis was evident but no gross atypia were noticed.

Gross examination of the specimen showed a well circumscribed $1 \times 1.5 \mathrm{~cm}$ yellowish white mass. Microscopically, bland spindle cells arranged in short fascicles and set in a myxoid to fibrous stroma with extravasations of red cells. Mitosis were evident but no gross atypical were noticed (Figure 4). Hence it was interrupted as nodular fasciitis. Post operatively recovery was uneventful. Three months follow up revealed; there was no evidence of facial nerve paresis and no residual facial contour deformity.

\section{Discussion}

Nodular Fasciitis can occur anywhere in the body. Most common location in adults being upper extremities (39-54\%), especially in the volvar aspect of the elbow. They can also be found on the trunk (15-20\%), lower extremities (16-18\%) and head \& neck region (7-20\%). In children however head and neck region is the most common site. Approximately $10 \%$ of all lesions are found in children. Nodular Fasciitis most commonly presents as a rapidly growing firm nodule of one month duration or less. Mostly as solitary, round to oval subcutaneous nodules with involvement of deep fascia and muscle in small percentage of patients. The cause is unknown but has often been linked to local injury or trauma. Radiographic evaluation with MRI renders an accurate assessment of the degree of soft tissue extension. Proper diagnosis requires histological confirmation. Nodular Fasciitis typically shows well circumscribed, encapsulated nodules composed of spindle cells. Treatment is most commonly by local surgical excision. However in some cases recurrence has been associated with incomplete excision of the lesion. When lesions recur alternate diagnosis of malignant process should be considered.

\section{Summary}

Nodular Fasciitis is an uncommon benign, idiopathic, proliferation of fibrous tissues. It is important to distinguish it from a malignant process because it can be successfully treated with complete local excision.

The importance of the nature of fascitid relates to the potential for overtreatment on the basis of microscopic features and its rapid growth. It should be emphasized that nodular fascitis is most common in the head \& neck region of children and should be considered in the differential diagnosis of all fibrous lesions of that region.

\section{References}

1. Tarren Vyas, Martin J Bullock, Robert D Hart, Jonathan R Trites, S Mark Taylor (2008) Nodular fasciitis of the zygoma. A case report Can J Plast Surg 16(4): 241-243.

2. Sung Tae Kim, Hyung-Jin Kim, Sun-Won Park, Jung Hwan Baek, Hong Sik Byun, et al. (2005) Nodular Fasciitis in the Head and Neck: CT and MR Imaging Findings. AJNR Am J Neuroradiol 26(10): 2617-2623.

3. IlanWeinreb, Allison J Shaw, Bayardo Perez-Ordo nez, John R Goldblum, Brian P Rubin (2009) Nodular fasciitis of the head and neck region: a clinic pathologic description in a series of 30 cases. J CutanPathol 36(11): 1168-1173.

4. Albert J Haddad, Sylvie Louise Avon, Cameron ML Clokie, George KB Sàndor (2001) Nodular fasciitis in oral cavity. J Can Dent Assoc 67(11): 664-6367.

5. S Mallina, S Rosalind, R Philip, S Harvinder, S Gurdeep, et al. (2007) Nodular Fascitis: A Diagnostic Dilemma. Med J Malaysia 62(5): 420-421.

6. Milan B Jovanovic, Ljiljana Cvorovic, Svetlana Milosevic, Sanja Milenkovi (2012) Unusual presentation of nodular fasciitis as a rapidly growing haemorrhagic temporal mass. Journal of Cranio-Maxillofacial Surgery 40(1): 33-35. 
7. Ashwani Kumar Sharma, Glynis Scott, Per-Lennart Westesson (2008) MRI sign of nodular fasciitis: a case report. Oral Surgery, Oral Medicine, Oral Pathology, Oral Radiology, and Endodontology 105(5): 53-56.

8. Han W, Hu Q, Yang X, Wang Z, Huang X (2006) Nodular fasciitis in the oro facial region. J Oral Maxillofac Surg 35(10): 924-927.

9. Chiarini L, Lo Russo L, Figurelli S, Procacci P, Rubini C, et al. (2008) Nodular fasciitis of the face: aesthetic considerations. Aesthetic Plast Surg 32(3): 560-562.

10. Reitzen SD, Dogan S, Har-El G (2009) Nodular fasciitis: a case series. J Laryngol Otol 123(5): 541-544.

11. Silva P, Bruce IA, Malik T, Homer J, Banerjee S (2005) Nodular fasciitis of the head and neck. J Laryngol Otol 119(1): 8-11.

12. Thompson LD (2002) Nodular fasciitis. Ear Nose Throat J 81(12): 830.

13. Shin JH, Lee HK, Cho KJ, Han MH, Na DG (2003) Nodular fasciitis of the head and neck: radiographic findings. Clin Imaging 27(1): 31-37.

14. Matusik J, Wiberg A, Sloboda J, Andersson O (2002) Fine needle aspiration in nodular fasciitis of the face. Cytopathology 13(2): 128-132.
15. Haas AF (1999) Nodular fasciitis of the forehead. Dermatol Surg 25(2): 140-142.

16. Coffin CM, Watterson J, Priest JR, Dehner LP (1995) Extrapulmonary inflammatory myofibroblastic tumor (inflammatory pseudotumor). A clinicopathologic and immunohistochemical study of 84 cases. Am J Surg Pathol 19(8): 859-872.

17. Zuber TJ, Finley JL (1994) Nodular fasciitis. South Med J 87(8): 842-844.

18. DiNardo LJ, Wetmore RF, Potsic WP (1991) Nodular fasciitis of the head and neck in children. A deceptive lesion. Arch Otolaryngol Head Neck Surg 117(9): 1001-1002.

19. Davies HT, Bradley N, Bowerman JE (1989) Oral nodular fascitis. Br J Oral Maxillofac Surg 27(2): 147-151.

20. Landau H, Wöckel W Dtsch Z Mund Kiefer Gesichtschir (1988) Diagnostic problems in nodular fasciitis of the face and neck. 12(5): 367-371.

21. Batsakis JG, Rice DH, Howard DR (1982) The pathology of head and neck tumors: spindle cell lesions (sarcomatoid carcinomas, nodular fasciitis, and fibrosarcoma) of the aerodigestive tracts, Part 14. Head Neck Surg 4(6): 499-513.

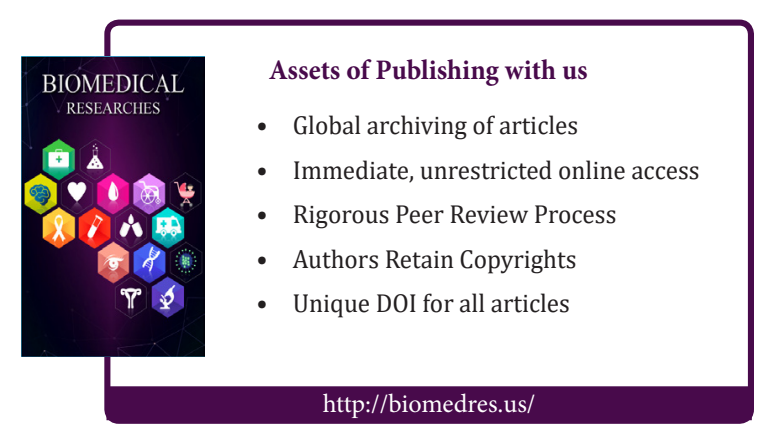

